\title{
Distribution of Methylenetetrahydrofolate Reductase rs1801133 Polymorphism in a Turkish Professional Cyclist Cohort
}

\author{
${ }^{1}$ İpek Yüksel, ${ }^{1}$ Canan Sercan, ${ }^{1}$ Sezgin Kapıcı, ${ }^{1}$ Betül Bıyı,, ${ }^{1}$ Tugba Kaman, ${ }^{1,2}$ Korkut Ulucan ${ }^{*}$ \\ ${ }^{1}$ Department of Molecular Biology and Genetics, Faculty of Engineering and Natural Sciences, Üsküdar University, \\ Istanbul, Turkey. ${ }^{2}$ Department of Medical Biology and Genetics, Faculty of Dentistry, Marmara University, Istanbul, \\ Turkey.
}

\begin{abstract}
Background. The determination of the genetic endowment of athletic performance in sports is an important step in developing personal training sessions or nutritional supplements for success in sports. Information about the genetic parameters responsible for these metabolisms will help sport's scientist to develop new insights for better performance. Muscle metabolism is one of the key points in better personal athletic performance. Objectives. The aim of this study is to analyze the distribution of the methylenetetrahydrofolate reductase enzyme (MTHFR) rs1801133 (C677T) genotype and allele distribution in a Turkish professional cyclist cohort. Methods. There were 25 Turkish cyclists enrolled in the study. Peripheral blood used for DNA isolation and the conventional polymerase chain reactionrestriction fragment length polymorphism (PCR- RFLP) methodology were used for genotyping. Results. There were $14(56 \%), 10(40 \%)$ and $1(4 \%)$ cyclist who had CC, CT, and TT genotypes, respectively. C allele was counted as 38 (76\%), and T alleles as $12(24 \%) .9(50 \%)$ of the male cyclist had CC, $8(44.4 \%)$ had CT and only 1 had TT (5.6\%) genotypes. C allele was counted as $26(72.2 \%)$, and the T allele as $10(27.8 \%)$ in the male cyclists. In the females, the respective genotypes for CC and CT were $5(71.4 \%)$ and $2(28.6 \%)$. C allele was counted as $12(85.7 \%)$ and $\mathrm{T}$ allele as $2(14.3 \%)$. Conclusion. In our cohort, both of the two genders, the CC genotype and $\mathrm{C}$ allele were found to be higher when compared to the other genotypes and $\mathrm{T}$ allele. Larger prospective studies focusing on the influence of MTHFR rs1801133 polymorphism in athletic performance are required for confirmation of our findings.
\end{abstract}

KEY WORDS: Athletic Performance, Epigenetic, Folic Acid, Sport Genomic, Supplement.

\section{INTRODUCTION}

Athletic performance is considered to be the combination of inherited genetic endowment and subsequent environmental factors. Current genetic research on athletic performance focuses on the polymorphisms that contribute significantly to the performance of athletes. Individual characteristics such as endurance, strength, power, muscle coordination, and motivation are all affected by genetic factors
(1). Sport genetics studies include a whole range of studies in the areas of identifying genes that influence athletic performance, clarifying the mechanisms of action, and determining their susceptibility to athletic performance. Not only in individual sports, but also in team sports, for improved success, it is important to organize training and nutrition programs, which are under the control of

*. Corresponding Author:

Korkut Ulucan

E-mail: korkutulucan@ hotmail.com 
genetic makeup (2). To have more information about the physical work capacities, such as biochemical, physiologic, and morphologic parameters, genomic data will provide valuable information for sport's scientists to optimize individual performance, training, adaptation.

There are several different cycling types, high-performance road, cross-country biking (XCMB), Downhill Mountain biking (DHMB) and bicycle motocross (BMX). Although they differ in cycling types, the cyclists' performance depends on both physiological and biomechanical parameters. Bicycle activities require long-term durability, quick power, and a maximum power for short and long distances. Biomechanical variables such as pedal force effectiveness and some morphological structures of cyclists such as muscle volume and muscle fiber type have effect on muscle performance and therefore, effect on cycling performance (3).

Methylenetetrahydrofolate reductase (MTHFR) is one of the major regulatory enzymes in a single carbon metabolism, which includes purine and pyrimidine (thymidine) synthesis. This enzyme converts 5,10-methylenetetrahydrofolate to 5methyltetrahydrofolate (5-methyl-THF; a cosubstrate for remethylation of homocysteine to methionine), which involves the forms of vitamin folate (4). The enzyme is coded by the MTHFR gene, which has been localized at $1 \mathrm{p} 36.3$, and consists of 11 exons (5). There are two common polymorphisms in the MTHFR; $677 \mathrm{C}>\mathrm{T}$ (rs1801133) transition leads to the conversion of Alanine into Valin (A222V) and 1298A $>C$ (rs1801131) the transversion leads from Glutamine to Alanine (Q429A) alteration (6). Both variants are related to reduced enzyme activity, leading to increased 5,10-methylenetetrahydrofolate and decreased 5-methyl-THF and therefore, effecting the DNA methylation metabolism.

Physical exercise stimulates adaptive changes that lead to a muscle phenotype with improved performance. Also, intense exercise causes DNA damage in professional athletes. DNA hypomethylation induces muscle growth and activation of factors that determine the differentiation of myoblasts, which promotes muscle mass (7). For cyclists, genetic variants suitable for the metabolism for explosive power phenotype and genetic variants suitable for the endurance capacities are expected. As reduced enzyme activity disturbs DNA methylation by effecting regulatory the mechanisms controlling genes involved in muscle hypertrophy, we aimed to analyze MTHFR C677T rs1801133 polymorphism in professional Turkish cyclists.

\section{MATERIALS AND METHODS}

Participants. A total of 25 cyclists, aged between 19-23 years, without any genetically transmitted diseases or in their first-degree relatives, were recruited for the study. To eliminate environmental factors, we excluded the ones who had vitamin and folate restriction. All the participants had the standard daily dose of Vitamin B supplement. The study was approved by the Üsküdar University Ethics Committee, and the study procedure was in accordance with the principles of the Declaration of Helsinki II. All the subjects provided written informed consent prior to enrollment.

DNA sample collection. The DNA was isolated from the peripheral blood using a PureLink DNA isolation kit (Invitrogen, Van Allen Way Carlsbad, Calif., USA). The procedures were conducted according to the provided manufacturers' instructions.

MTHFR C677T genotyping. The amplification of the polymorphic region was maintained by using the primers 5 '-TGA AGG AGA AGG TGT CTG GGG GA-3' and 5'-AGG ACG GTG CGG TGA GAG TG-3'. The PCR reactions were conducted in a $50-\mu \mathrm{l}$ mixture containing 100 ng genomic DNA, $5 \mu 110 \mathrm{X}$ Taq buffer, $3 \mu \mathrm{l} 25 \mathrm{mM} \mathrm{MgCl} 2,1 \mu \mathrm{l} 0.2 \mathrm{mM}$ dNTP, $2 \mu \mathrm{l} 1 \mu \mathrm{M}$ primers and 2 units Taq DNA polymerase. The reaction was completed after 38 cycles; after the pre-denaturation at $94^{\circ} \mathrm{C}$ for 5 min, all the cycles had the denaturation at $94^{\circ} \mathrm{C}$ for $45 \mathrm{sec}$, annealing at $62^{\circ} \mathrm{C}$ for $45 \mathrm{sec}$, and the extension at $72^{\circ} \mathrm{C}$ for $45 \mathrm{sec}$. The final extension at $72^{\circ} \mathrm{C}$ for $10 \mathrm{~min}$ completed the amplification process. In order to determine the allelic types, an overnight HinfI (Thermo Scientific, USA) digestion at $37^{\circ} \mathrm{C}$ was performed. The undigested 198-bp amplicon was determined as the wild-type and named CC genotype; whereas the mutant TT genotype was digested into 175and 23-bp fragments. The heterozygous 
individuals (CT genotypes) exhibited the 198-,

173- and 23-bp band patterns (Figure 1).

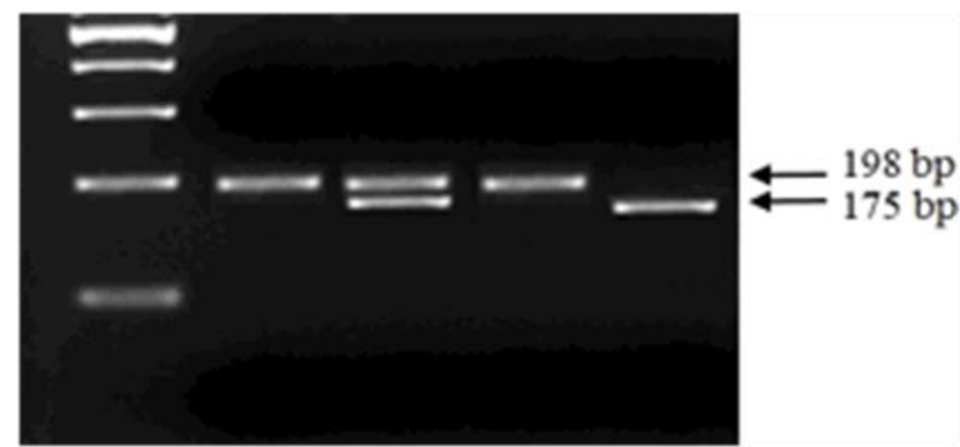

Figure 1. The agarose gel electrophoresis view of the MTHFR rs1801133 polymorhism. The first lane represents the $100 \mathrm{bp}$ molecular marker, lane 2 and 4 are CC (undigested), lane 3 is CT, and lane 5 is the TT genotype.

\section{RESULTS}

There were 25 Turkish national cyclists who participated in our study. 14 cyclists had CC (56\%), $10(40 \%)$ had CT, and only $1(4 \%)$ had TT genotypes. When the allelic distributions were examined, the $\mathrm{C}$ allele was counted as $38(76 \%)$, and $\mathrm{T}$ alleles as $12(24 \%)$. In our cohort, the CC genotype and $\mathrm{C}$ allel were dominating when compared to the other genotypes and $\mathrm{T}$ allele. When we examined the gender distribution, 9
(50\%) of the male cyclists had CC, $8(44.4 \%)$ had $\mathrm{CT}$, and 1 had TT $(5.6 \%)$ genotypes. The $\mathrm{C}$ allele was counted as $26(72.2 \%)$, and the T allele as 10 $(27.8 \%)$ in the male cyclists. In the females, the $\mathrm{CC}$ and $\mathrm{CT}$ genotypes were detected as $5(71.4 \%)$, and $2(28.6 \%)$ respectively. We detected no TT genotypes in the female cyclists. The $\mathrm{C}$ allele was counted as $12(85.7 \%)$ and the $\mathrm{T}$ allele as 2 $(14.3 \%)$. The genotype and allelic distributions for the MTHFR gene are summarized in Table 1.

Table 1. The numbers and percentages of the MTHFR rs1801133 genotype and alleles in the cyclists.

\begin{tabular}{|c|c|c|c|c|c|}
\hline & \multicolumn{3}{|c|}{ MTHFR Genotype } & \multicolumn{2}{|c|}{ Allele Frequency } \\
\hline & $\mathrm{CC}$ & CT & TT & $\mathrm{C}$ & $\mathrm{T}$ \\
\hline Female Cyclists & $5(71.4 \%)$ & $2(28.6 \%)$ & $0(0 \%)$ & $12(85.7 \%)$ & $2(14.3 \%)$ \\
\hline Male Cyclists & $9(50 \%)$ & $8(44.4 \%)$ & $1(5.6 \%)$ & $26(72.2 \%)$ & $10(27.8 \%)$ \\
\hline Total & $14(56 \%)$ & $10(40 \%)$ & $1(4 \%)$ & $38(76 \%)$ & $12(24 \%)$ \\
\hline
\end{tabular}

\section{DISCUSSION}

Muscle cells display a number of molecular processes under regular high intensity exercise. The primary mechanisms as an adaptation to regular exercise are the muscle mass increases, which are mainly supplied by the proliferative activation and myogenic differentiation of the mononuclear satellite cells that fuse with the enlarging myofibers (7). These changes in the muscle cells are considered to be under the control of the DNA methylation processes, in which the MTHFR plays crucial roles, especially in the methylation process of the genes responsible for generating new adaptive proteins. Therefore, it is important to have knowledge about the genetic parameters affecting this metabolism. MTHFR rs1801133 is one of the most important functional polymorphism in this regard. DNA hypomethylation has recently been shown to be an important factor in exerciseinduced adaptation in the skeletal muscles (8).

In the present study, we analyzed 25 professional cyclists, some of whom represent at National levels. $56 \%$ of our athletes had CC 
genotype, $40 \%$ had CT and $4 \%$ had TT genotypes. $\mathrm{C}$ allele was $76 \%$ and $\mathrm{T}$ allele $24 \%$. In both the male and female cyclists, the $\mathrm{CC}$ genotypes and $\mathrm{C}$ alleles were higher than the other genotypes (CT and TT) and T allele. When we consider the general population, the TT genotype and $\mathrm{T}$ allele are relatively underrepresented. Teruzzi et al. (2011) analyzed 77 elite athletes and compared them to 54 sedentary controls. They reported that $63.5 \%$ of the elite athletes had a CT genotype, $26.9 \%$ had CC, and the remaining had TT genotypes. In an early study, Dinc et al. (2016) analyzed 48 Turkish soccer players that played in some of the A2 teams of the Turkcell Super League and Bank Asya Major League in Turkey and compared them to 48 sedentary individuals in terms of the MTHFR rs1801133 polymorphism and in some anthropometric and biochemical blood parameters. In their cohort, they identified a significant difference between MTHFR rs1801133 polymorphic alleles and the analyzed parameters; the soccer players were found to have lower levels of triglyceride, total cholesterol and LDL cholesterol levels, and higher levels of folate than the sedentary individuals. They also reported that the participants who had TT genotypes had a lower level of Vitamin B12 and folate and a higher level of Hcy than the participants carrying CC and CT genotypes. However, they did not compare the allelic differences between the soccer players and the sedentary individuals. When we compared the genotype results with these previous studies, there were some differences in terms of the genotype percentages. Thus, the genotype results had some differences within the different populations and within the same populations. This fact may explain our different results when compared to the earlier ones.

Banting et al. (2015) analyzed five different SNPs, including the MTHFR rs 1801133 in male Polish (108 endurance, 100 power/ sprint and 440 sedentary) and Russian (70 endurance, 107 power/ sprint and 104 sedentary) cohorts. In the Polish samples, in the endurance athletes, the percentages were 49.40, and 11 for the CC, CT, and TT genotypes, respectively. For power/ sprint athletes, the respective genotype percentages for CC, CT and TT genotypes were 51, 40 and 9. Our results were in agreement with the Polish cohort, indicating the dominancy of the CC genotype and
C allele. A Russian cohort from the same study for endurance athletes showed similar results to ours; their respective genotype percentages for CC, CT, and TT were 51, 43 and 6. However, in the power/ sprint athletes, the genotype percentages for CC, CT, and TT were 41, 49 and 10, respectively. In their Polish and Russian cohort, they observed no statistically significant difference between the genotypes of athletes and the sedentary individuals.

Other functional polymorphism in the MTHFR is the $\mathrm{A}>\mathrm{C}$ transversion located at position 1298 (A1298C, rs1801131). This variation leads to a change of glutamate into alanine at the C-terminal regulatory domain of MTHFR protein, and confer reduced enzyme activity (11). Zarebska et al. (2013) analyzed the distribution of the 1298A $>C$ variant in 302 Polish and 842 Russian athletes, for which they divided the athletes into four groups: endurance, strength/endurance, sprint/strength, and strength/ endurance. They also enrolled 1540 control participants onto the study and concluded that not only the C677T, but also the A1298C polymorphism is an important biomarker in athletic performance. They found that the $\mathrm{C}$ allele seems to be beneficial in sprint-strength and strength activities when compared to other athlete groups and control subjects.

\section{CONCLUSION}

It is a well-known fact that individuals have different responses to similar training: from a lack of adaptive response to extreme overload. Studies to date have shown that individuals having the same genotype for a given DNA respond to the same exercises much more similarly to those with different genotypes, indicating that genes have crucial roles in the determination of individual differences to physical activities. In addition, some genetic parameters have important roles in the recovery metabolism of muscles during the resting times after intensive exercise. Having information about them will enable coaches to set up individual improved training sessions depending on the genomic variations.

One of the major limitations of our study was the number of subjects. In the present study, we had 25 cyclists enrolled for the study. To have more precise results, we should have more samples for the genotype. Our second limitation 
was the lack of biochemical results such as the homocysteine and methionine levels. These parameters may be affected by other environmental factors, for example, stress, nutrition, or endocrinal conditions. To date, it is very clear that DNA methylation does not solely control exercise-induced gene expression (13) as there are other complex cellular transductional network systems which modify the DNA methylation (14). However, despite these limitations, this initial report supplies information about the allelic distribution of C677T polymorphism in Professional Turkish cyclists.

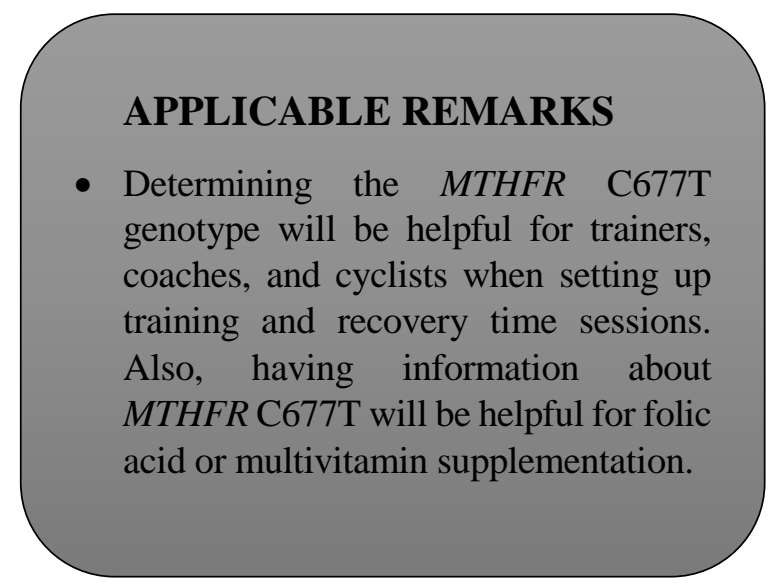

\section{REFERENCES}

1. Ulucan K, Yalcin S, Akbas B, Uyumaz F, Konuk M. Analysis of Solute Carrier Family 6 Member 4 Gene promoter polymorphism in young Turkish basketball players. The journal of Neurobehavioral Sciences. 2014;1(2):37-40.

2. Ulucan K. Literature Review of Turkish Sportsmen in Terms of ACTN3 R577X Polymorphism. Clinical and Experimental Health Sciences. 2016;6(1):44-7.

3. Lanferdini FJ, Bin RF, Cunha GS, Lopes AL, Castro FAS, Oliveira AR, et al. Relationship between physiological and biomechanical variables with aerobic power output in Cycling. Journal of Science and Cycling. 2014;3(1):28.

4. Ulucan K, Karahan M, Sağlam E. Biochemical and molecular effects of folic acid metabolism to Parkinson, Alzheimer, bipolar and schizophrenic disorders. Anatolian Journal of Psychiatry. 2013;14(4):378- 82.

5. Goyette P, Sumner JS, Milos R, Duncan AM, Rosenblatt DS, Matthews RG, et al. Human methylenetetrahydrofolate reductase: isolation of cDNA, mapping and mutation identification. Nature Genetics. 1994;7(2):195-200.

6. Uğuz N, Erden G, Güngör O, Bal C, Yıldırımkaya M. Determination of the frequency of MTHFR C677T and MTHFR A1298C polymorphisms in persons with polymorphic MTHFR gene. Journal of Clinical and Experimental Investigations. 2012;3(4):472-6.

7. Terruzzi I, Senesi P, Montesano A, La Torre A, Alberti G, Benedini S, et al. Genetic polymorphisms of the enzymes involved in DNA methylation and synthesis in elite athletes. Physiological genomics. 2011;43(16):965-73.

8. Barres R, Zierath JR. DNA methylation in metabolic disorders. The American journal of clinical nutrition. 2011;93(4):897s-900..

9. Dinc N, Yucel SB, Taneli F, Sayin MV. The effect of the MTHFR C677T mutation on athletic performance and the homocysteine level of soccer players and sedentary individuals. Journal of human kinetics. 2016;51:61-9.

10. Banting LK, Pushkarev VP, Cieszczyk P, Zarebska A, Maciejewska-Karlowska A, Sawczuk MA, et al. Elite athletes' genetic predisposition for altered risk of complex metabolic traits. BMC genomics. 2015;16:25.

11. Castro R, Rivera I, Ravasco P, Jakobs C, Blom HJ, Camilo ME, et al. 5,10-Methylenetetrahydrofolate reductase 677C-->T and 1298A-->C mutations are genetic determinants of elevated homocysteine. QJM : monthly journal of the Association of Physicians. 2003;96(4):297-303.

12. Zarebska A, Ahmetov, II, Sawczyn S, Weiner AS, Kaczmarczyk M, Ficek K, et al. Association of the MTHFR $1298 \mathrm{~A}>\mathrm{C}$ (rs1801131) polymorphism with speed and strength sports in Russian and Polish athletes. Journal of sports sciences. 2014;32(4):375-82.

13. Barres R, Yan J, Egan B, Treebak JT, Rasmussen M, Fritz T, et al. Acute exercise remodels promoter methylation in human skeletal muscle. Cell metabolism. 2012;15(3):405-11.

14. Coffey VG, Hawley JA. The molecular bases of training adaptation. Sports medicine (Auckland, NZ). 2007;37(9):737-63. 